\title{
Possibilities and limits of use plastic constructions in fruit growing technologies
}

\author{
Gonda, I. ${ }^{1}$, Vaszily, B. ${ }^{1} \&$ Soltész, M. $^{2}$ \\ ${ }^{1}$ University of Debrecen Centre for Agricultural and Applied Economic Sciences \\ H-4032 Debrecen, 138 Böszörményi Street, Hungary \\ ${ }^{2}$ College of Kecskemét, Faculty of Horticulture, H-6000 Kecskemét, 1-3. Erdei Ferenc Square
}

\begin{abstract}
Summary: On the Experimental Station Pallag of Debrecen University different combinations of fruit species and rootstocks have been raised under and without plastic foil cover in 2002. The growth and productivity of the grafts was our objective of comparison. Results revealed substantial differences in fruit set and yield depending on species and varieties. Sweet and sour cherry varieties grew much shorter under the plastic cover, whereas apricots, peaches and plums set fruit much more eagerly compared with the trees outside the plastic cover.

Outside the plastic cover, the trees were much more developed at the beginning of their fruiting period. In spite of that, the growing processes were more intense under the foil. The differences are allegedly due to the repeated summer pruning necessary under the restricted space of the foil, on the other hand, due to the root concurrence because of the dense planting.

Regarding the inner properties of the fruits, soluble solids, sugar and acids were higher outside, whereas macro- and mezzo-elements (P, $\mathrm{K}, \mathrm{Ca}, \mathrm{Mg}$ ) were more abundant in fruits grown under the foil cover.

Further efforts to explore those relations with other varieties and rootstocks are justified.
\end{abstract}

Key words: plastic foil, covered fruit growing technology, vegetative growth

\section{Introduction}

The use of plastic foil for growing constructions is relatively a young tendency, which began about 100 years ago. First of all small fruits - mainly strawberry - were grown in closed, transparent tunnels. Information on larger, woody plants grown under foil is still scarce except on vinestocks of table grapes.

As a consequence of economic changes during the last twenty years, horticultural enterprises growing vegetables or ornamental plants gave up their job because of economical reasons, but the equipment, constructions, framework and plastic foil are maintained. They could be used for fruit growing without conspicuous investments. For the first approach, the foil cover does not need heating. Other advantages and disadvantages are to be considered too. Balmer et al. $(2005,2008)$ exposed their experiences. For instance, the lack of regular pollination impairs the fruit set, and during the blooming period, April and May, adverse conditions of overheating or late frosts, may cause drop of flowers or fruits set. The atmosphere under the foil cover used to be too humid, which is moderated by ventilation through the side walls. All the same, vegetative growth is stimulated, blooming as well as the drop of fruits set is more intense Tartachnyk \& Blanke (2004).

On the base of theoretical considerations and practical experiences, advantages and disadvantages are listed as follows.

\section{Advantages:}

- Prevention or mitigation of damages caused by excessive weather conditions, such as:

- Perfect protection of foliage and fruits against stormy winds,

- hail damages,

- and avoid late or early frosts in spring and autumn respectively, and

- damages causing by birds.

- Provision of higher temperatures than outside the cover, which results in higher performance of plants regarding vegetative as well as generative growth.

- Earlier maturity, which may earn premium through higher prices.

- Phytosanitary advantages are due to lower pressure of infections in the isolated space.

- To fight diseases and predators by gasification.

\section{Disadvantages:}

- The price of construction and its amortisation as a component of costs.

- The concern to avoid harmful overheating during summertime by ventilation.

- Phytosanitary risks because of high air humidity under the cover.

- Absolute necessity of regular water supply. 
- Necessity of an exact system of plant nutrition.

- Difficulties to provide adequate pollination depending of species or variety.

- At blooming time, because of the low temperature no visiting insects are available, which could be substituted by bumblebees to be raised for additional costs.

- The low light intensity may induce unexpected growing habits of the plants.

- Higher speed in senescence (premature balding processes).

- Weak colour development on the fruits.

- Poor inner quality of fruits (soluble solids).

- The restricted space of the construction put a limit of production and yield.

- Because of increased vegetative vigour more phytotechnical interventions are needed (pruning, cutting back of branches).

- The dust covering the leaves ought to be washed by water sprays.

- Fruit varieties need chilling during the rest period, which means the necessity of expose the plants to low temperature by opening the cover for a longer time, which is a costly component.

- The spatial properties of the construction need to be met with super dense planting proper to intense fruit growing systems.

The exaggerated vegetative growth is due to the higher soil temperatures causing quick availability of nitrogen with deleterious consequences in fruit set, fruit growth, allegedly by the disruption of the balanced system between source and sink in the plant. Preponderance of vegetative growth is expressed by more and larger leaves than outside the foil cover. The chlorophyll content of sweet cherry leaves was $45-59 \mu \mathrm{g} / \mathrm{cm}^{2}$, which is sufficient, moreover, more than $50 \mu \mathrm{g} / \mathrm{cm}^{2}$ leaf area means saturation for photosynthese (Tartachnyk \& Blanke, 2004).

As by the listed arguments, we tried to exhaust the demonstration of economical considerations regarding the use of plastic constructions for growing fruits. It is evident from the list that disadvantages are more numerous than the advantages. In spite of that, the security of production, higher quality, primeur prices for anticipated maturity promise higher profitability may push the decision of growers in favour of the use foil constructions.

\section{Materials and methods}

Experiments with foil covered constructions to be compared with the same plants outside the foil were located at the Experimental Station and Institute for Regional Development, Pallag, of the Debrecen University.

Data of the Pastic cover:

- Matrial: PVC foil

- Width: $10 \mathrm{~m}$

- Length: $30 \mathrm{~m}$

- Height: $4.5 \mathrm{~m}$

- The matter of throating with zinc coated iron.
Planting was made in April 2003 under foil and outside at the same time, in the sandy soil with $1 \%$ humus content.

Planting design:

- Under foil: $2.2 \mathrm{~m} \mathrm{X} 1.0 \mathrm{~m}$

- Outside: $5 \mathrm{~m}$ X $1.5 \mathrm{~m}$

Trees are trained for a slender spindle with a main axis. Outside the space is larger and the lower branches are longer.

The observed fruit trees planted to both treatments are:

- Peach: 'Max7', 'Champion', 'Silver King', 'Silver Giant'

- Plum: 'Jojo', 'Tophit'

- Sweet cherry: 'Linda', 'Germersdorfi3', 'Katalin'

All fruit varieties are grafts on seedling stocks.

For providing pollinating partners for 'Katalin' cherry, 'Linda' and 'Germersdorfi' are planted. Unfortunately, grubs killed the pollinating trees, therefore, cut branches of blooming trees were taken to fulfil their function.

Blooming dates under the foil started earlier, i.e. about early and mid of March depending on species. At those dates, no insects are moving outside the foil cover, therefore, bumble bees have been raised to visit the flowers.

Generally, the necessary phytotechnical interventions are performed at the end of winter, and during the summer 2-3 times the so called "summer pruning".

The soil tilling was performed by manual and mechanical cultivators.

Phytosanitary treatments are made by sprayers carried on the back. The soil around the trunks was densely $(20 \mathrm{~cm})$ mulched with straw in order to moderate warming up of soil.

Under the foil, irrigation was established according to the dripping system. However, during the hot summer periods, flooding was applied, when the side walls of the foil cover were rolled up, and each tree received 20-25 1 water around the dish dug around the base, in order to compensate for the water lost by evaporation in the heat.

\section{Results}

\section{Experiences regarding fruit development}

A general impression was in all fruit species and varieties that fruit set is impaired under the foil as the heaviest concern of cultivation. Sweet cherry is most affected. In spite of remarkable flower density (Photo 1), fruit set was hopelessly poor in all varieties observed.

As due to the extra high temperatures, blooming ensued synchronically in all varieties, therefore principally mutual fertilisation could be expected. In order to substitute free living pollinating insects, bumble bee hives are provided, yet in vain. We surmised that the anomalous "ecological" conditions interacted with the genetically set exigencies of the varieties. The question deserves more observations of some important sweet cherry varieties.

Peach and plum varieties, on the other hand, set fruit abundantly each year, as far as a manual thinning of the fruits set was necessary. 


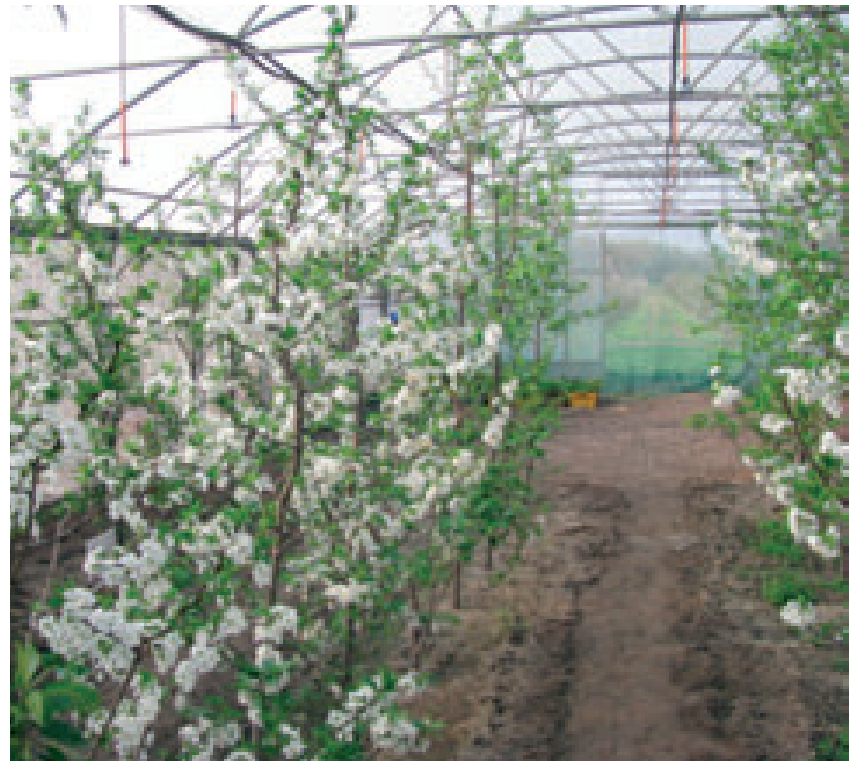

Photo 1. Cherry trees in full bloom.

Peach being considered as being originating from warmer sites may explain that property. For plums, those arguments cannot be applied, regarding ecological claims being more similar to that of e.g. sour cherry's. The potentials of fruit setting are seemingly subject to another system of genetical principles in plums than in cherries and are more stable.

By all means, the experience let us state that the problem of finding adequate mutually compatible polliniser varieties and the tendency to set fruit under anomalous conditions are interesting aspects to develop new fruit growing technologies. For some fruit species, the first random approach of the problem proved to be quite successful (apricots, peaches and plums) as having been grown under a plastic foil (Vaszily \& Gonda, 2011).

According to marketing considerations, sweet cherry should be the candidate number one for this new branch of fruit growing. There are a lot of questions, which need to be answered to develop the technology.

\section{Experiences related to the quality of fruits}

In 2010, fruit of two plum varieties, Jojo and Tophit has been compared regarding the inner properties of quality depending on the method of growing (Table 1).

Obviously, soluble solids, sugar and acid content were lower in fruits of both varieties grown under the foil cover, than outside of it. Organoleptic tests proved the same. Contents of macro- and micro elements ( $\mathrm{P}, \mathrm{K}, \mathrm{Ca}, \mathrm{Mg}$ ) showed the opposite, i.e. the superiority of under foil grown fruits. The differences are highly probable consequences of the remarkable variation in content of soluble solids.

On the other hand, seasonal effects are also involved because the excessively abundant precipitation diluted the elements outside the foil cover and the soil was saturated with water, whereas under the cover humidity was more regular.
Table 1. Parameters of inner quality of plum fruits grown under plastic foil or outside the cover (Debrecen-Pallag, 2010)

\begin{tabular}{|l|c|c|c|c|l|}
\hline \multicolumn{1}{|c|}{$\begin{array}{c}\text { Parameters } \\
\text { observed } \\
\text { under } \\
\text { foil } \\
\text { cover }\end{array}$} & $\begin{array}{c}\text { Jojó } \\
\text { outside }\end{array}$ & $\begin{array}{c}\text { Tophit } \\
\text { under } \\
\text { foil } \\
\text { cover }\end{array}$ & $\begin{array}{c}\text { Tophit } \\
\text { outside } \\
\text { the } \\
\text { cover }\end{array}$ & Reliability \\
\hline $\begin{array}{l}\text { Soluble solids } \\
\text { m/m\% }\end{array}$ & 13.0 & 14.2 & 10.4 & 16.0 & $\pm 0.2 \% \mathrm{~A}$ \\
\hline Sugar m/m\% & 11.8 & 13.0 & 9.50 & 14.2 & $\pm 8 \% \mathrm{R}$ \\
\hline $\begin{array}{l}\text { Sum of acids } \\
\mathbf{m} / \mathbf{m} \%\end{array}$ & 0.41 & 0.52 & 0.42 & 0.36 & $\pm 10 \% \mathrm{R}$ \\
\hline Ash m/m\% & 0.34 & 0.32 & 0.43 & 0.44 & $\pm 0.3 \% \mathrm{~A}$ \\
\hline Ca mg/kg & 48.3 & 43.5 & 74.3 & 57.5 & $\pm 10 \% \mathrm{R}$ \\
\hline K mg/kg & 1563 & 1377 & 1765 & 1537 & $\pm 10 \% \mathrm{R}$ \\
\hline $\mathbf{M g ~ m g / k g}$ & 62.8 & 53.2 & 66.4 & 51.2 & $\pm 10 \% \mathrm{R}$ \\
\hline P mg/kg & 193 & 129 & 182 & 122 & $\pm 10 \% \mathrm{R}$ \\
\hline
\end{tabular}

\section{Observations regarding growth and vegetative performance of trees}

Cultivation under the foil cover increases the length of the growing period by roughly one and a half month (beginning by 3 weeks earlier and finishing by 3 weeks later). This fact is univocally expressed in the higher vegetative performance of the plants. Measurements prove that after the beginning of the fruiting age - which ensues about 1-2 years earlier under the foil than outside depending on species and variety - the vegetative performance used to be superior by $40-50 \%$ in some cases than outside the cover. The additional growth is expressed in the number and length of shoots, however, the thickness of the shoots is much more inferior because the prolonged and continuous time of growth in length. In the case of peaches, at least three times during the summer relatively severe so called "green pruning" ought to be performed.

In Figure 1, cross section areas of peach tree trunks are shown as parameters of complex growth.

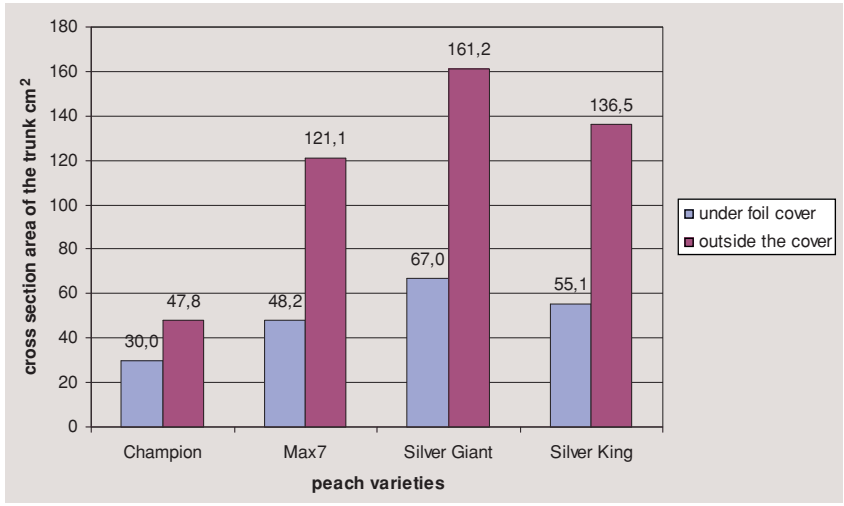

Figure 1. Cross section area of the trunks of peach trees grown under foil cover and outside the cover at an age of 8 years (Debrecen-Pallag, 2010)

It seems to be contradictory that the trunks of peach trees grown outside the foil cover are thicker - by $60 \%$ - than of those grown under the foil cover. The inferior thickening may 
have consequences as the repeated (2-3) summer pruning and the substantially more dense planting or higher concurrence of the roots as inhibiting moments.

In the slender spindle crowns of 8 year old peach trees, the thickness of the main axis has been measured at a height of $150 \mathrm{~cm}$, and compared as presented in Figure 2.

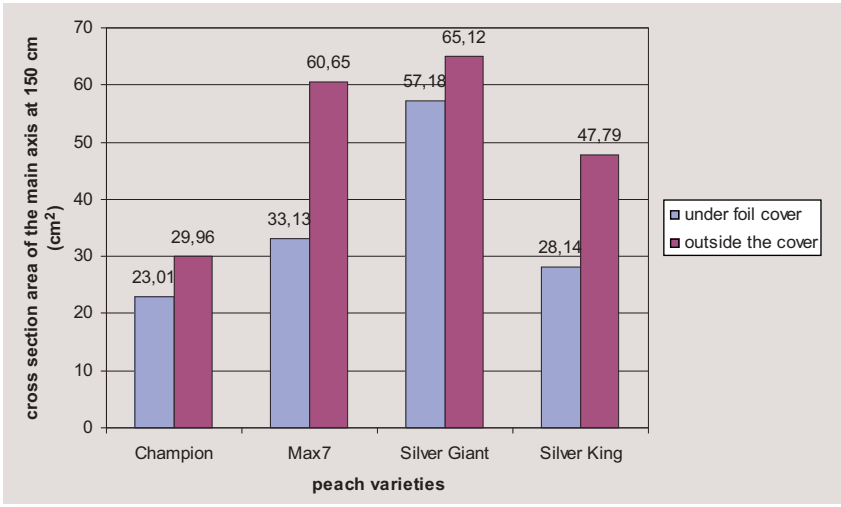

Figure 2. The cross section area of the main axis of 8 year old peach trees at $150 \mathrm{~cm}$ height and grown under plastic foil cover or freely, without cover (Debrecen-Pallag, 2010)

The superiority of freely grown trees is maintained at 150 $\mathrm{cm}$ height of the main axis, but the differences are much smaller and effects of the particular variety are variable.

Cross section areas measured at a height of $200 \mathrm{~cm}$ are visible in Figure 3. Some contradictory tendencies appear seemingly as varietal effects.

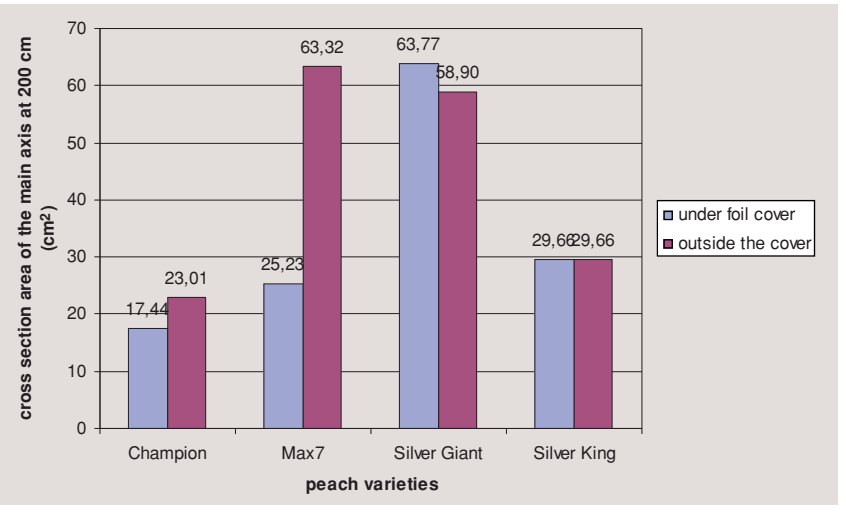

Figure 3. The cross section area of the main axis of 8 year old peach trees at $200 \mathrm{~cm}$ height and grown under plastic foil cover or freely, without cover (Debrecen-Pallag, 2010)

The Zahn index representing the relation between trunk and the branches is presented in Figure 4.

In two freely grown peach varieties, the Zahn index reached and surpassed the 0.6 value typical for peaches, in two varieties, there was no difference between cover and freely grown trees with 0.4 indices. The suitability of varieties for growing under foil or for intense growing technology may differ as expressed by parameters of growth.

As an expression of growing properties is the number of specific growing points, which equals with the number of buds, which start growing and may characterise the ability of ramification. Relevant data are presented in Figure 5.

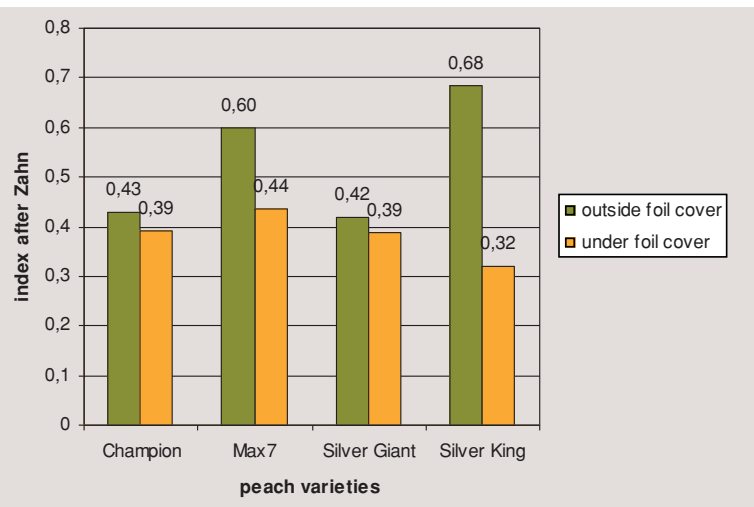

Figure 4. The Zahn index of 8 year old peach trees grown under foil cover and outside of it (Debrecen-Pallag, 2010)

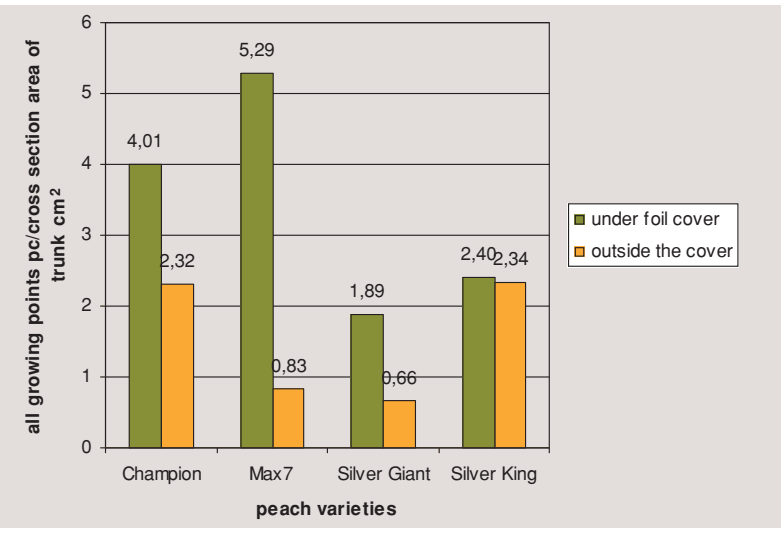

Figure 5. Specific number of growing points of peach trees grown under foil cover or outside the cover at an age of 8 years (Debrecen-Pallag, 2010)

The Figure shows that in the case of three varieties, the foil cover stimulated the sprouting of buds, i.e. the ability of ramification (branching). We have to appreciate this trait because of the restricted space under the foil needed thin out severely the dense canopy of foliage to provide enough light for photosynthesis.

The growing vigour of peaches encourages the frequent appearance of secondary branching. The number of secondary branches specified to one metre of primary shoots is visualised on Figure 6.

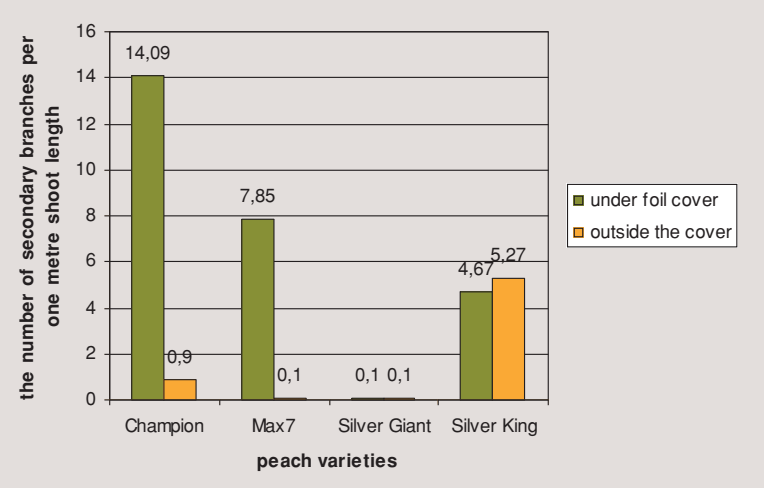

Figure 6. The specified number of secondary branches on 8 year old peach trees grown under plastic foil and outside of it (Debrecen-Pallag, 2010) 
Let us observe that in two peach varieties the secondary branches were many times more abundant under the foil cover than outside of it. One variety did not sprout at all, whereas 'Silver King' formed invariably the same number of secondary branches.

The same tendencies are expressed in the length of secondary shoots, as seen in Figure 7.

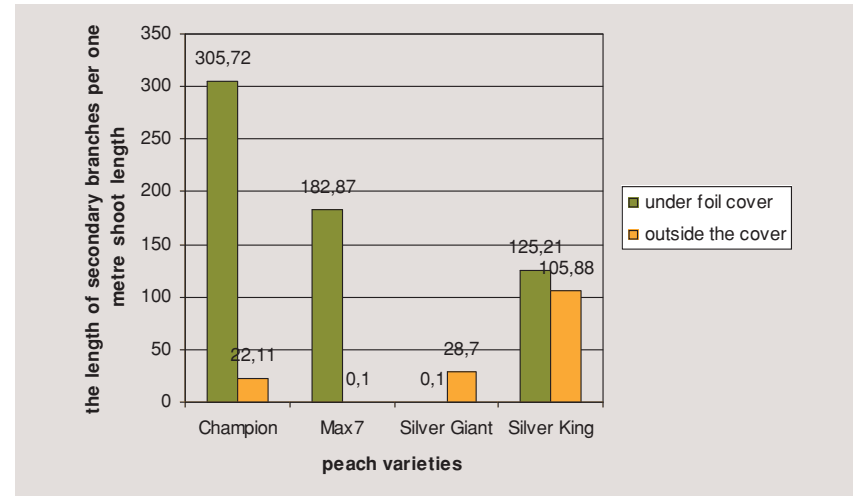

Figure 7. Specific length of secondary shoots (per one metre) developed on8 year old peach trees grown under plastic foil and outside the cover (Debrecen-Pallag, 2010)

On three varieties out of four, the secondary shoots were longer on trees grown under the plastic foil cover than outside the cover, but 'Silver Giant' produced only outside a few. On variety 'Max7', almost any secondary shoots were outside the cover, whereas 'Silver Giant' produced secondary growth only outside the cover.

In crown parts of different age, the volume of shoot growth was not dependent on growing technology, they were rather subject to inherited growing patterns of the particular variety. For example, the forming of fruiting spears are preferably found free growing trees (outside the cover), and practically it ensued on both varieties. However, it should be remarked that under the plastic foil, conspicuous cases of shoots getting bald has been stated, which is also an important cause of dwindling in growing points. Intense growing processes are at the same time paralleled by accelerating processes of senescence expressed also in bald sections on shoots.

\section{Phytosanitary experiences}

Exaggerated humidity should be avoided by regular aeration especially during the summer. Our experiences emphasise in all fruit species the occurrence the red spider, powdery mildew on peaches, lead glance on plums as dangerous damages. Sanitary measures ought to be brought up to date. Once we met the appearance of scales too. The lack of fruit moths and leaf damaging pests was a positively assent.

Acknowledgement: This work was supported by NFÜ TECH- 08- A4/2-2008-0138,

TECH-08-A3/2- 2008-0373 and TÁMOP -4.2.2/B-10/12010-0024 grants.

\section{References}

Balmer, M. \& Blanke, M. M. (2005): Developments in high dendity cherries in Germany. Acta Hort.667.

Balmer, M., Kunz, A. \& Blanke, M. M. (2005): Verführung von Süsskirschen unter geschlossener Folie. Erwerbs-Obstbau 47. p.

Blanke, M. M. \& Balmer, M. (2008): Cultivation of Sweet Cherry under Rain Covers. Acta Hort. 795: 479-484.

Gonda I. \& Vaszily B. (2011): A fóliasátor alatti gyümölcstermesztés lehetőségei. KLÍMA-21 Füzetek, 64: 144-155.

Tartachnyk, I. \& Blanke, M. M. (2004): Effect of delayed fruit harvest on photosynthesis, transpiration and nutrient remobilization of apple leaves. New Phytologist. 164: 442-450. 